\title{
The Immunological Roles of Periostin/Tumor-Associated Macrophage Axis in Development of Dermatofibrosarcoma Protuberans
}

\author{
TAKU FUJIMURA, AYA KAKIZAKI, YOTA SATO, KAYO TANITA, SADANORI FURUDATE and SETSUYA AIBA
}

Department of Dermatology, Tohoku University Graduate School of Medicine, Sendai, Japan

\begin{abstract}
Background/Aim: Dermatofibrosarcoma protuberance (DFSP) is a fibrohistiocytic tumor of intermediate malignancy characterized by slow infiltrative growth and a high tendency to recur locally. Periostin is involved in modulating cell function and inducing the production of proinflammatory cytokines, chemokines, and matrix metalloproteinases (MMPs) from tumor-associated macrophages (TAMs) to promote fibrosis and tumor growth. This study aimed to examine the cancer stroma of DFSP, focusing on TAMs-related proteins and MMPs. Patients and Methods: Using immunohistochemical staining and DNA microarray database, we evaluated periostin, CD163, CD206, MMP1 and MMP12 in 10 cases of DFSP and dermatofibroma. Results: Dense deposits of periostin as well as a substantial number of $C D 163^{+}$TAMs were detected at the peripheral areas of DFSP. Moreover, MMP1 and MMP12, that were selected by using a DNA microarray database of monocyte-derived macrophages, were observed in the TAMsdetected area. Conclusion: Increased levels of MMP1 and MMP12 on TAMs in the peripheral areas of DFSP might contribute to local invasion.
\end{abstract}

Dermatofibrosarcoma protuberance (DFSP) is a fibrohistiocytic tumor of intermediate malignancy characterized by slow infiltrative growth and a high tendency to recur locally. DFSP characteristically grows seemingly at random with microscopic finger-like projections emanating from the center of the tumor (1). Although several reports have suggested the relationship between the biological behavior of DFSP and matrix metalloproteinases (MMPs), the mechanisms to induce MMPs in the lesional skin of DFSP is still unclear (2-5).

Correspondence to: Taku Fujimura, Department of Dermatology, Tohoku University Graduate School of Medicine, Seiryo-machi 11, Aoba-ku, Sendai, 980-8574, Japan. Tel: +81 227177271, Fax: +81 227177361, e-mail: tfujimura1@mac.com

Key Words: DFSP, periostin, tumor-associated macrophages, MMP1, MMP12.
Tumor-associated macrophages (TAMs) promote an immunosuppressive environment in the tumor-bearing host by various pathways (6). Among them, previous reports have indicated that TAMs modulate and induce neovascularization by producing angiogenc factors, including (MMPs). Indeed, in combination with VEGF (vascular endothelial growth factor), MMPs play a crucial role in TAMs (6). For example, $\mathrm{CD} 63^{+}$TAMs produced high levels of MMP9 and MMP11 to promote tumor development in cutaneous squamous cell carcinoma (7). Another report has also suggested that TAMs could produce specific MMPs by stimulation of cancerspecific stromal factors such as periostin (8). These reports suggested that MMPs play important roles in developing a series of skin cancers. In the present study, we investigated the stroma of DFSP and benign fibrous tumor dermatofibroma (DF) with a focus on TAMs and TAMrelated immunoreactive molecules in cancer stroma.

\section{Materials and Methods}

Materials. The following antibodies (Abs) were used for immunohistochemical staining: rabbit polyclonal Abs for human periostin (Abcam, Tokyo, Japan), CD163 (Novocastra, Tokyo, Japan), CD206 (LifeSpan BioScience, Seattle, WA), MMP1 (Biobyt, Cambridge, UK), and MMP12 (R \& D systems, Minneapolis, MN).

Patients, tissue samples and immunohistochemical staining. For immunohistochemical staining, archival formalin-fixed paraffinembedded skin specimens were collected from 10 patients with DF and 10 patients with DFSP who were treated in the Department of Dermatology at Tohoku University Graduate School of Medicine (Table I). All patients gave written informed consent. Before the antigen retrieval procedure, we used $0.3 \%$ $\mathrm{H}_{2} \mathrm{O}_{2}$ in methanol to inhibit endogenous peroxidase. These samples were analysed for single staining of periostin, CD163, CD206, MMP1, and MMP12. Briefly, formalin-fixed paraffinembedded tissue samples were sectioned at $4 \mathrm{~mm}$ and deparaffinized. After autoclaving for antigen retrieval treatment, the sections were blocked with goat serum (Gibco, Tokyo, Japan), for 10 minand exposed to primary antibodies at $4^{\circ} \mathrm{C}$ overnight. Antibody binding was demonstrated via 3-amino-9-ethylcarbazole (Nichirei Bioscience, Tokyo, Japan). 
Table I. Summary of the 10 cases of DFSP and DF of this study.

\begin{tabular}{|c|c|c|c|c|c|c|c|}
\hline & & Age & Gender & Locasion & POSTN & MMP1 & MMP12 \\
\hline \multirow[t]{11}{*}{ DFSP } & Case 1 & 38 & M & Abdomen & $2+$ & $1+$ & $1+$ \\
\hline & Case 2 & 57 & M & Shoulder & $1+$ & $1+$ & $2+$ \\
\hline & Case 3 & 5 & M & Medial malleolus & $2+$ & $2+$ & $2+$ \\
\hline & Case 4 & 41 & $\mathrm{~F}$ & Back & $2+$ & $2+$ & $2+$ \\
\hline & Case 5 & 51 & $\mathrm{~F}$ & Chest & $1+$ & $1+$ & $2+$ \\
\hline & Case 6 & 35 & F & Lower leg & $1+$ & $1+$ & $1+$ \\
\hline & Case 7 & 49 & F & Ingrown & $2+$ & $2+$ & $2+$ \\
\hline & Case 8 & 53 & M & Back & $2+$ & $2+$ & $1+$ \\
\hline & Case 9 & 42 & F & Abdomen & $1+$ & $1+$ & $2+$ \\
\hline & Case 10 & 23 & F & Chest & $1+$ & $1+$ & $2+$ \\
\hline & & Age & Gender & Location & POSTN & MMP1 & MMP12 \\
\hline \multirow[t]{10}{*}{ DF } & Case 1 & 66 & M & Buttock & $2+$ & $1+$ & $2+$ \\
\hline & Case 2 & 43 & M & Back & $1+$ & $1+$ & $1+$ \\
\hline & Case 3 & 47 & M & Shoulder & $1+$ & $1+$ & $2+$ \\
\hline & Case 4 & 28 & $\mathrm{~F}$ & Populiteal fossa & $2+$ & $2+$ & $2+$ \\
\hline & Case 5 & 62 & $\mathrm{~F}$ & Upper arm & $2+$ & $2+$ & $2+$ \\
\hline & Case 6 & 48 & M & Upper arm & $2+$ & $2+$ & $2+$ \\
\hline & Case 7 & 43 & M & Upper arm & $2+$ & $1+$ & $1+$ \\
\hline & Case 8 & 44 & $\mathrm{~F}$ & Back & $2+$ & $1+$ & $2+$ \\
\hline & Case 9 & 25 & F & Face & $1+$ & $1+$ & $2+$ \\
\hline & Case 10 & 62 & F & Foot & $1+$ & $2+$ & $2+$ \\
\hline
\end{tabular}

1+: Weak; 2+: intense. DFSP: Dermatofibrosarcoma protuberans; POSTN: periostin; DF: dermatofibroma; MMP: matrix metalloproteinase.

DNA microarray database. The data discussed in this publication have been deposited in NCBI's Gene Expression Omnibus and are accessible through GEO Series accession number GSE70821 (8). (http://www.ncbi.nlm.nih.gov/geo/query/acc.cgi?acc=GSE70821).

Culture of M2 macrophages from human peripheral blood monocytes stimulated with periostin and IL-4. CD14+ cells were isolated from the peripheral blood mononuclear cells (PBMCs) of healthy donors by using MACS beads (CD14 microbeads, Miltenyi Biotec, CA) according to the manufacturer's protocol. CD14+ monocytes $\left(2 \times 10^{5} / \mathrm{ml}\right)$ were cultured in complete RPMI-1640 medium (Sigma Aldrich, Tokyo, Japan) containing $100 \mathrm{ng} / \mathrm{ml}$ of recombinant human M-CSF (Peprotech, London, UK) for 5 days as previously reported (9). On the fifth day, the monocyte-derived M2 macrophages (M2M) were treated with IL-4 (Peprotech, London, UK) $(20 \mathrm{ng} / \mathrm{ml})$ together with periostin ( $\mathrm{R}$ and $\mathrm{D}$ system, Minneapolis, MN) $(100 \mathrm{ng} / \mathrm{ml})$. This study was approved by the ethics committee of Tohoku University Graduate School of Medicine, Sendai, Japan (2014-1-687).

RNA extraction, assessment of quality,reverse transcription, and quantitative real-time PCR experiments. Total RNA was extracted by using an RNeasy Micro kit (Qiagen, Courtaboeuf, France) in accordance with the manufacturer's instructions. The RNA was eluted with $4 \mu \mathrm{l}$ of RNase-free water. DNase I treatment (RNaseFree DNase Set; Qiagen) was performed to remove contaminating genomic DNA. Reverse transcription was performed with the SuperScript VILO cDNA Synthesis Kit (Invitrogen, Carlsbad, CA).
Amplification reactions were performed with an Mx 3000P RealTime Quantitative PCR System (Stratagene, Tokyo, Japan). The thermal cycling conditions were: $3 \mathrm{~min}$ for polymerase activation at $95^{\circ} \mathrm{C}$ followed by 40 cycles at $95^{\circ} \mathrm{C}$ for $5 \mathrm{sec}$ and $60^{\circ} \mathrm{C}$ for $20 \mathrm{sec}$, and finally maintained at $4^{\circ} \mathrm{C}$. Relative mRNA expression levels were calculated for each gene and each time point after normalization against GAPDH by using the $\Delta \Delta \mathrm{Ct}$ method.

\section{Results}

Periostin deposits, CD163 ${ }^{+}$TAMs, and CD206 cells in DFSP. We evaluated deposits of periostin, that are reported to play a role in fibrosing diseases (10) and tumor progression (11), in the stromal area of DFSP. Immunohistochemical staining for periostin revealed dense deposits of periostin at the peripheral areas of the DFSP in all 10 cases of DFSP tested (Figure 1A, $\mathrm{B}$, Table I). In contrast, there were no periostin deposits in the central areas of the tumor (Figure 1A). As a previous report suggested, periostin modulates the mRNA expression of chemokines and MMPs (8). In another report, periostin recruited M2 tumor-associated macrophages (TAMs) to promote the growth of glioblastoma multiforme (12). Based on the above findings, we hypothesized that TAMs stimulated by periostin might play roles in the pathogenesis of DFSP and DF. Therefore, we performed immunohistochemical staining for 

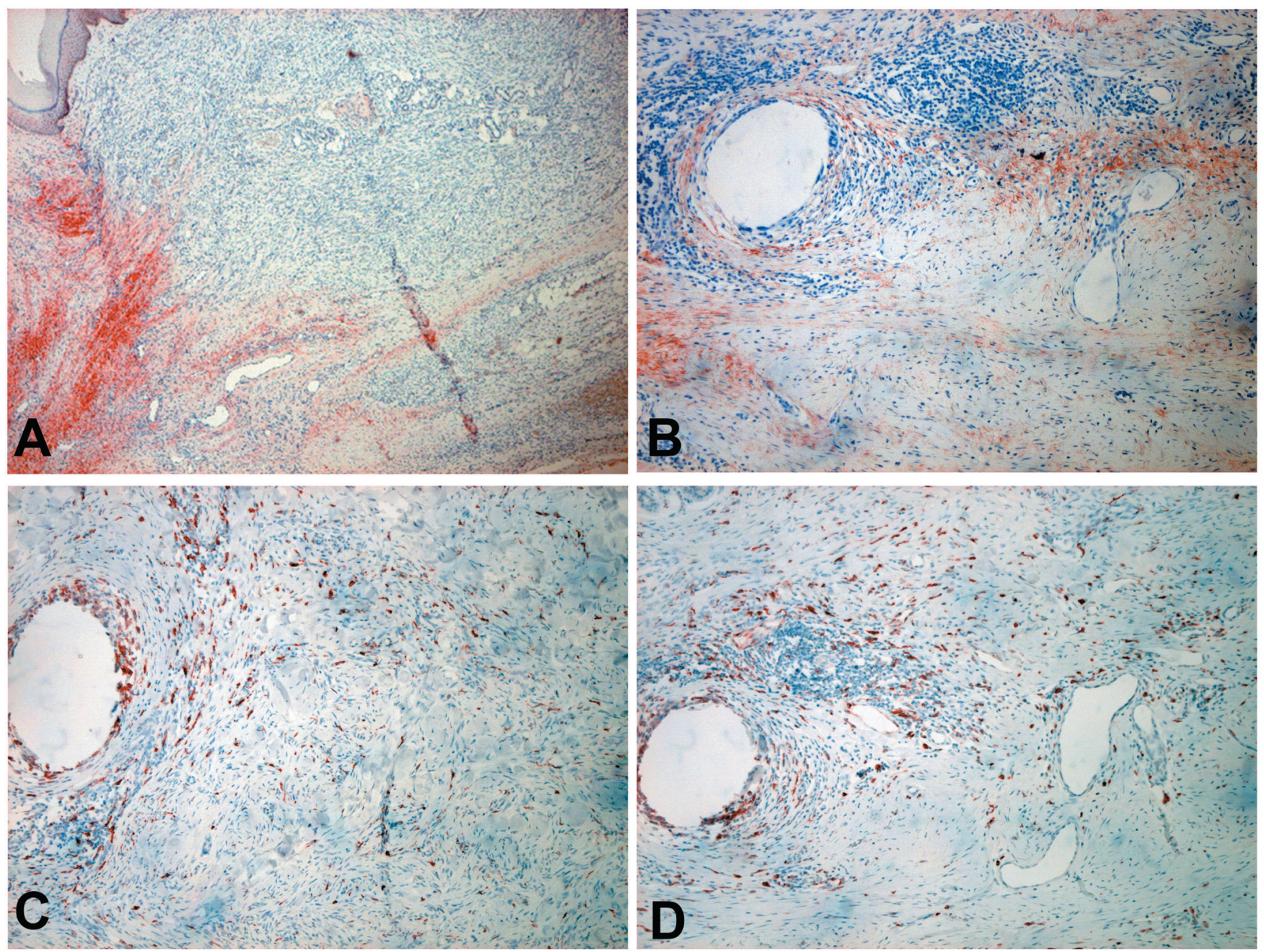

Figure 1. TAMs and cancer stroma in the lesional skin of DFSP. Paraffin-embedded tissue samples from a patient with DFSP were deparaffinized and stained with anti-periostin $A b(A, B)$, anti-CD163Ab $(C)$, and anti-CD206 Ab (D). Sections were developed with 3-amino-9-ethylcarbazole. Original magnification; $100 \times(A), 200 \times(B-D)$.

CD163 and CD206 in DFSP. Substantial numbers of CD163+ TAMs (Figure 1C) and CD206 ${ }^{+}$cells (Figure 1D) were detected in all cases of DFSP.

Periostin deposits, CD163+ TAMs, and CD206 cells in DF. Next, we evaluated the deposits of periostin, CD163+ TAMs and $\mathrm{CD}_{206}{ }^{+}$cells in the stromal area of the benign fibrous tumor DF. In the stroma of DF, dense deposits of periostin were diffusely detected in the central areas of the tumor in all 10 cases (Figure 2A and B). Similarly to DFSP, substantial numbers of $\mathrm{CD}_{163^{+}}$TAMs (Figure 2C) and CD206 ${ }^{+}$cells (Figure 2D) were detected in all cases of DF. MMP1- and MMP12-bearing cells in the lesional skin of DFSP and DF. Substantial numbers of $\mathrm{CD} 206^{+}$cells were detected in the stroma of DFSP and DF, which suggests that
IL-4 stimulates TAMs in the lesional skin of DFSP and DF $(13,14)$. Therefore, we further hypothesized that periostin and IL-4 might modulate the function of CD163 ${ }^{+}$TAMs. Indeed, periostin deposits were observed in the same areas as $\mathrm{CD} 163^{+}$TAMs and $\mathrm{CD} 206^{+}$cells. As we previously reported, DNA microarray analysis (GEO Series accession number GSE70821: http://www.ncbi.nlm.nih.gov/geo/ query/acc.cgi?acc $=\mathrm{GSE} 70821$ ) revealed that in vitro stimulation of $\mathrm{CD}_{163}{ }^{+}$-monocyte-derived macrophages (MoM) by periostin augments only the mRNA expression of MMP12 among the MMPs (8). Using another DNA microarray database, IL-4 stimulation augments the mRNA expression of MMP1 and MMP12 among the MMPs (GEO Series accession number GSE75829: http://www.ncbi.nlm. nih.gov/geo/query/acc.cgi?acc=GSE75829). 

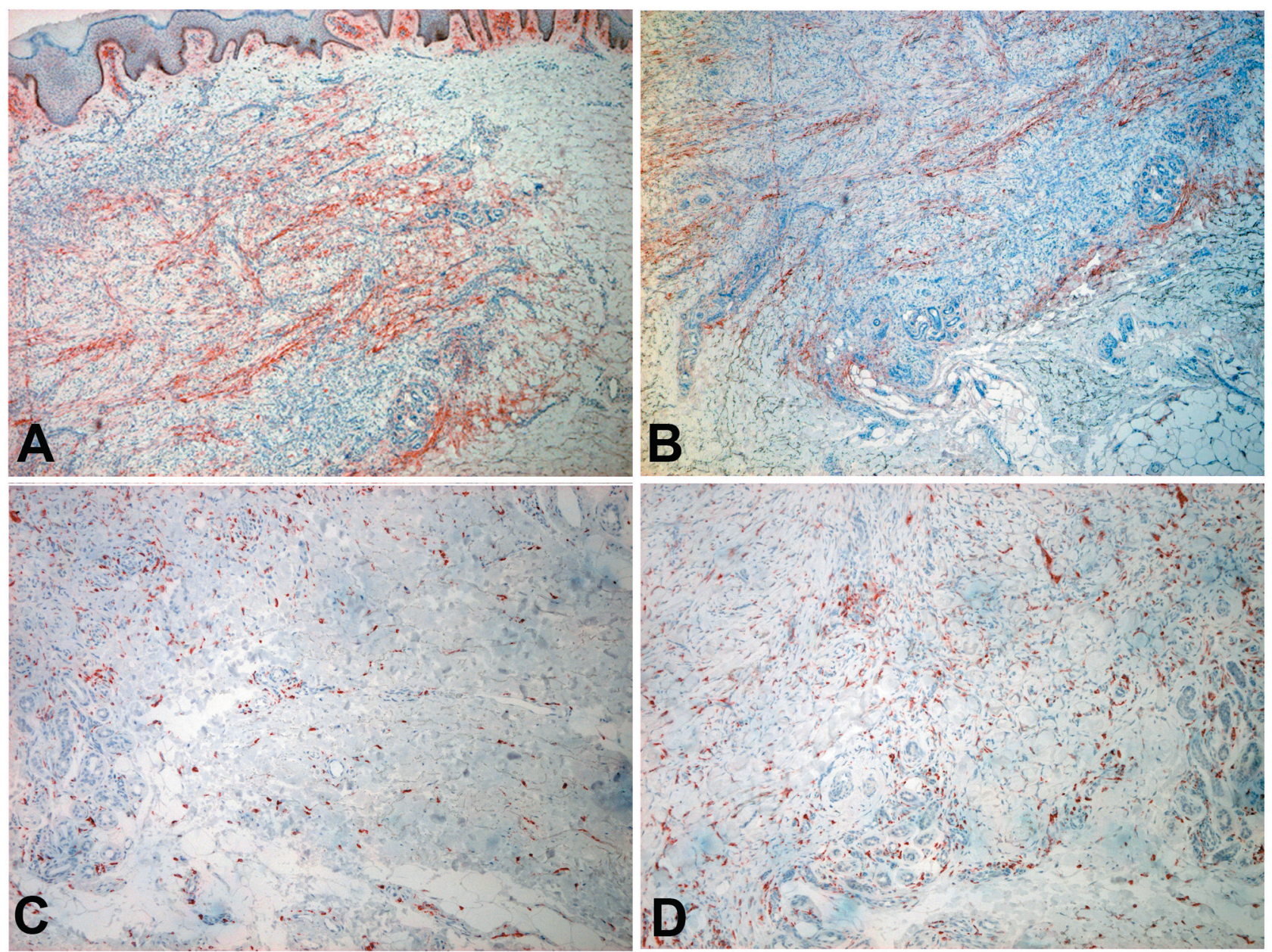

Figure 2. TAMs and cancer stroma in the lesional skin of DF. Paraffin-embedded tissue samples from a patient with dermatofibroma were deparaffinized and stained with anti-periostin $A b(A, B)$, anti-CD163Ab $(C)$, and anti-CD206 $A b(D)$. Sections were developed with 3-amino-9ethylcarbazole. Original magnification; $100 \times(A), 200 \times(B-D)$.

Therefore, to confirm the results of the previous microarray data, we performed quantitative RT-PCR analysis of MoM that were treated with or without $100 \mathrm{ng} / \mathrm{ml}$ periostin and $20 \mathrm{ng} / \mathrm{ml}$ IL-4. We evaluated the mRNA expression of MMP1 and MMP12. Consistent with the results of the DNA microarray analysis, these results demonstrated that stimulation with periostin and IL-4 augmented the expression of MMP1 and MMP12 mRNA, while stimulation with only periostin augmented the expression of MMP12 mRNA (Figure 3).

The production of MMP1 and MMP12 in DFSP and DF. To validate the quantitative RT-PCR results obtained by using MoM, we evaluated the MMP1- and MMP12-expressing cells in the lesional skin of each tumor. Both in DFSP and
DF, MMP1-bearing cells (Figure 4A, B) and MMP12bearing cells (Figure 4C, D) were scattered in the areas infiltrated by $\mathrm{CD} 163^{+}$macrophages.

\section{Discussion}

Periostin is an extracellular matrix protein that is involved in modulating cell functions. Also, it interacts with its functional integrin receptor molecules to induce the production of proinflammatory cytokines from keratinocytes, thereby accelerating Th2-type immune responses in allergeninduced skin inflammation (15). The deposition of periostin occurs in fibrosing skin diseases, such as keloids, hypertrophic scars (16). Concerning tumor development, Zhou et al. have reported that periostin from glioblastoma 

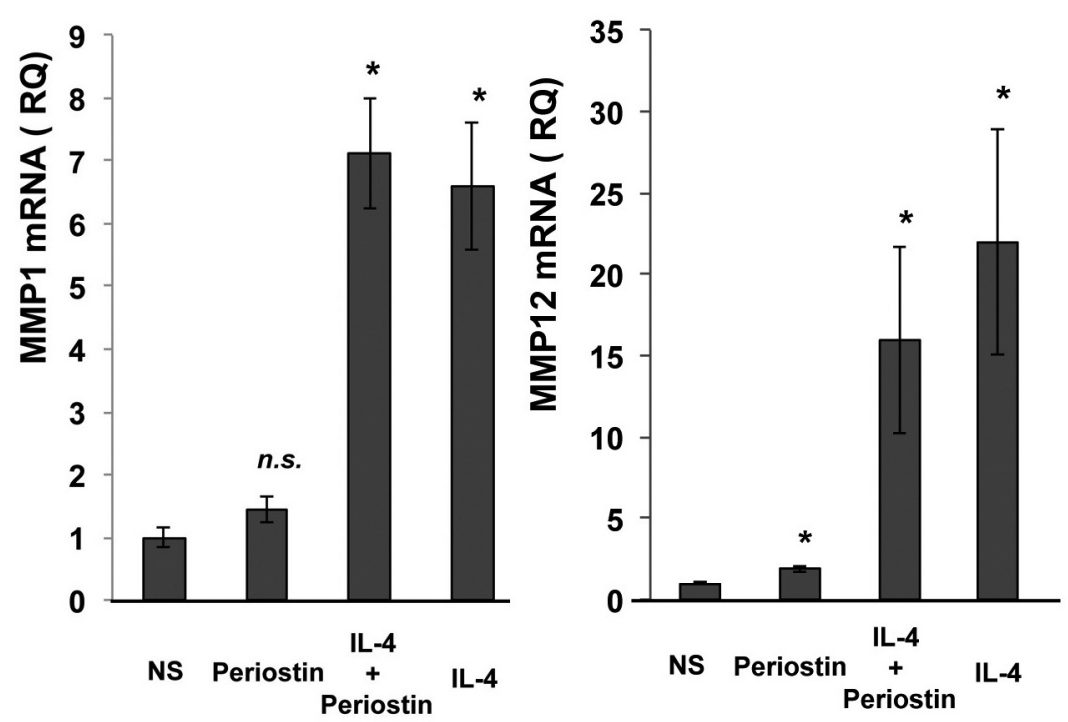

Figure 3. mRNA expression of MMP1 and MMP12 on macrophages stimulated by periostin and IL-4. Monocyte-derived macrophages were induced from PBMCs from healthy donors, as described in Materials and Methods. On the fifth day, the monocyte-derived macrophages were treated with periostin $(100 \mathrm{ng} / \mathrm{ml})$ with or without IL-4 $(20 \mathrm{ng} / \mathrm{ml})$. Six hours after stimulation, total RNA was recovered from macrophages and amplified, labeled, and analyzed. Quantitative real-time PCR for validation of the DNA microarray results was conducted to determine the number of copies of cDNA for each MMP, and the mRNA expression levels relative to the mRNA expression levels were calculated for each gene and time point after normalization against GAPDH by using the $\triangle \triangle C t$ method. The data from each donor were obtained in triplicate assays, and then the mean $\pm S D$ was calculated. Averages of data from at least three independent experiments are shown.

stem cells recruits monocytes from peripheral blood, which results in an increase of M2-like TAMs and promotes the growth of glioblastoma multiforme (12). Periostin has also been reported to stimulate monocyte-derived macrophages to produce a series of chemokines and MMPs that might be connected with the cancer formation of mycosis fungoides $(8,17)$. These reports suggest that chemokine production from TAMs stimulated by periostin play crucial roles in the progression of various tumors.

TAMs comprise of a heterogeneous population of cells that compose cancer stroma and express an array of effector molecules that inhibit the anti-tumor immune responses (18). For example, TAMs secrete chemokines, such as CCL5, CCL20, and CCL22, which recruit natural regulatory $\mathrm{T}$ (nTreg) cells $(18,19)$. On the other hand, CCL5 is reported to polarize naive $\mathrm{T}$ cells to Th2 cells to promote tumor growth in a mouse breast cancer model (20). In addition, as we have previously reported, TAMs produce CCL17 to recruit Tregs in the lesional skin of extramammary Paget's disease (9). These reports suggest that TAMs play a central role in maintaining the immunosuppressive tumor microenvironment and strongly correlate with the pathogenesis of various cancers.

Regarding macrophage differentiation, Gordon and Martinez proposed IL-4 as one of the cytokines that induces the differentiation of monocytes into mature macrophages in a second stage of activation in which they produce $\mathrm{Th} 2$ chemokines $(9,13,14)$. These in vitro data suggest that IL-4 polarizes macrophages into type 2 (M2) macrophages. Notably, IL-4 is necessary for the expression of CD206 on macrophages $(9,13,14)$. In our present study, CD206 ${ }^{+}$cells densely infiltrated the areas with $\mathrm{CD} 163^{+}$TAMs in all cases of DFSP and DF. Therefore, we hypothesized that TAMs in DFSP might be stimulated by both periostin and IL-4. By using a DNA microarray database of monocyte-derived macrophages stimulated by periostin and IL-4, we detected that periostin and IL-4 augment the mRNA expression of MMP1 and MMP12. Indeed, we validated our hypothesis based on the microarray information by immunohistochemical staining of MMP1 and MMP12 in DFSP.

The expression of both MMP1 and MMP12 correlated to the risk and prognosis of various cancers (21) and could be a biomarker of various cancers (22). As Foley and Kuliopulos have reviewed, MMP1/collagenase-1 degrades type I, type II, and type III collagen to promote tumor invasion (23). In addition, Kim et al. have reported MMP1 as a mediator of circulating tumor cell infiltration into mammary tumors to promote the progression of mouse breast cancer (24). On the other hand, MMP12 is a macrophage-secreting proteinase that promotes immune 

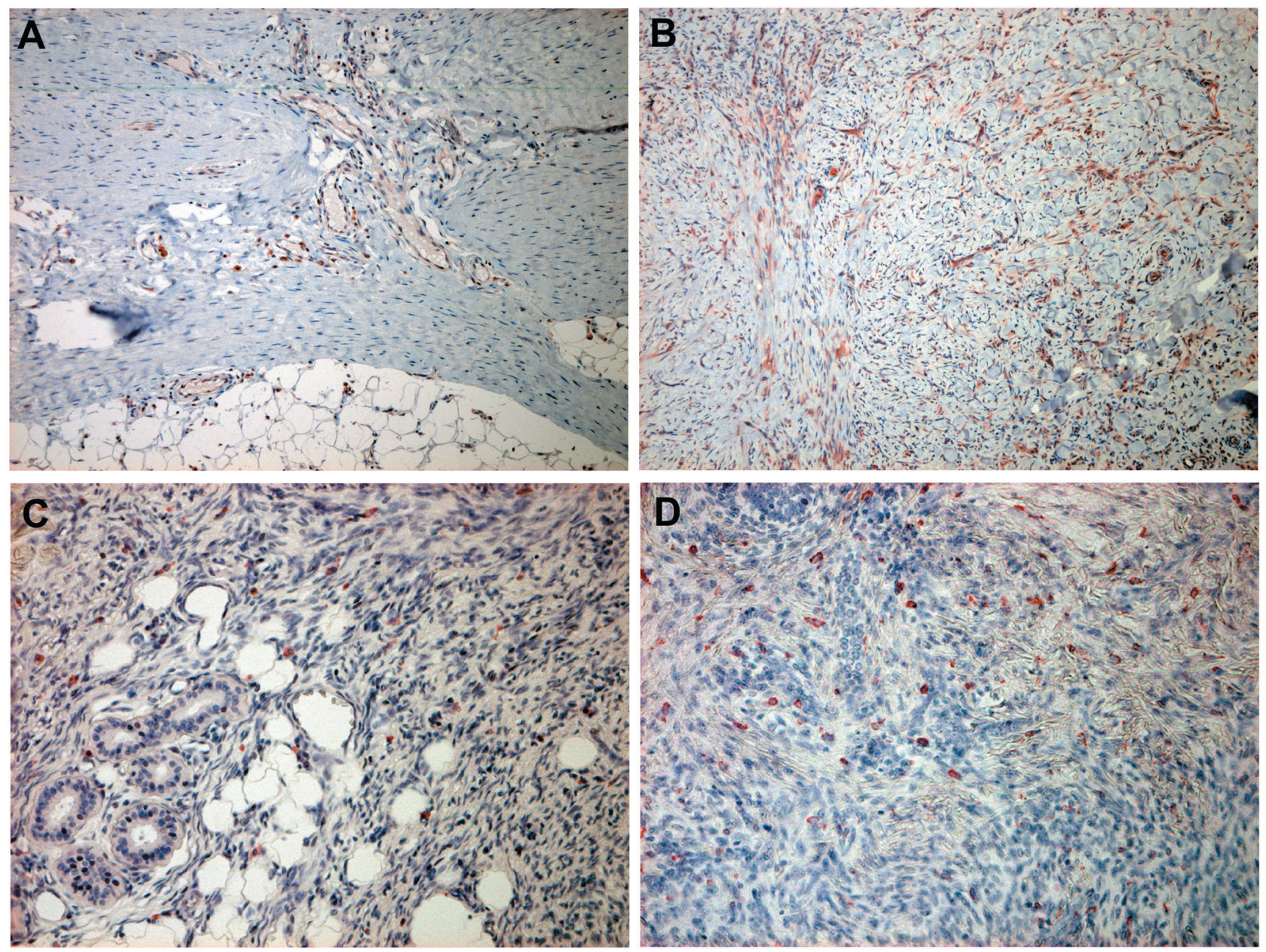

Figure 4. The expression of MMP1 and MMP12 in the lesional skin of DFSP and DF. Paraffin-embedded tissue samples from a patient with DFSP $(A, C)$ and $D F(B, D)$ were deparaffinized and stained with anti-MMP1 $A b(A, B)$, and anti-MMP12 Ab $(C, D)$. Sections were developed with 3amino-9-ethylcarbazole. Original magnification; 200× (A-D).

suppression and tumor progression in lung adenocarcinoma (25), hepatocellular carcinoma (26), and head and neck squamous cell carcinoma (27). For example, MMP12 expression is associated with the extracapsular spread and correlated with nodal metastasis in head and neck squamous cell carcinoma (27). These reports suggest that the increased levels of MMP1 and MMP12 on TAMs in the peripheral areas of DFSP could be a possible mechanism of local invasion of DFSP. Since immunohistochemical analysis only examines a single time point within the life of a tumor, further studies are needed to gain additional insight into the pathomechanisms of DFSP.

\section{Conflicts of Interest}

The Authors have no conflicts of interest to declare.

\section{References}

1 Laskin WB: Dermatofibrosarcoma protuberans. CA Cancer J Clin 42: 116-125, 1992.

2 Undén AB, Sandstedt B, Bruce K, Hedblad M and Stahle-Bäckdahl M: Stromelysin-3 mRNA associated with myofibroblasts is overexpressed in aggressive basal cell carcinoma and in dermatofibroma but not in dermatofibrosarcoma. J Invest Dermatol 107: 147-153, 1996.

3 Thewes M, Worret WI, Engst R and Ring J: Stromelysin-3 (ST3): immunohistochemical characterization of the matrix metalloproteinase (MMP)-11 in benign and malignant skin tumours and other skin disorders. Clin Exp Dermatol 24: 122-126, 1999.

4 Cribier B, Noacco G, Peltre B and Grosshans E: Stromelysin 3 expression: a useful marker for the differential diagnosis dermatofibroma versus dermatofibrosarcoma protuberans. J Am Acad Dermatol 46: 408-413, 2002. 
5 Kim HJ, Lee JY, Kim SH, Seo YJ, Lee JH, Park JK, Kim MH, Cinn YW, Cho KH and Yoon TY: Stromelysin-3 expression in the differential diagnosis of dermatofibroma and dermatofibrosarcoma protuberans: comparison with factor XIIIa and CD34. Br J Dermatol 157: 319-324, 2007.

6 Fujimura T, Kakizaki A, Furudate S, Kambayashi Y and Aiba S: Tumor-associated macrophages in skin: How to treat their heterogeneity and plasticity. J Dermatol Sci 83: 167-173, 2016.

7 Pettersen JS, Fuentes-Duculan J, Suárez-Fariñas M, Pierson KC, Pitts-Kiefer A, Fan L, Belkin DA, Wang CQ, Bhuvanendran S, Johnson-Huang LM, Bluth MJ, Krueger JG, Lowes MA and Carucci JA: Tumor-associated macrophages in the cutaneous SCC microenvironment are heterogeneously activated. J Invest Dermatol 131: 1322-1330, 2011.

8 Furudate S, Fujimura T, Kambayashi Y, Kakizaki A and Aiba S: The possible interaction between periostin expressed by cancer stroma and tumor-associated macrophages in developing mycosis fungoides. Exp Dermatol 25: 107-112, 2016.

9 Fujimura T, Kambayashi Y, Furudate S, Asano M, Kakizaki A and Aiba S: Receptor activator of nuclear factor kappa-B ligand (RANKL) promotes the production of CCL17 from RANK+ M2 macrophages. J Invest Dermatol 135: 2884-2887, 2015.

10 Uchida M, Shiraishi H, Ohta S, Arima K, Taniguchi K, Suzuki S, Okamoto M, Ahlfeld SK, Ohshima K, Kato S, Toda S, Sagara H, Aizawa H, Hoshino T, Conway SJ, Hayashi S and Izuhara K: Periostin, a matricellular protein, plays a role in the induction of chemokines in pulmonary fibrosis. Am J Respir Cell Mol Biol 46: 677-686, 2012.

11 Orecchia P, Conte R, Balza E, Castellani P, Borsi L, Zardi L, Mingari MC and Carnemolla B: Identification of a novel cell binding site of periostin involved in tumour growth. Eur $\mathrm{J}$ Cancer 47: 2221-2229, 2011.

12 Zhou W, Ke SQ, Huang Z, Flavahan W, Fang X, Paul J, Wu L, Sloan AE, McLendon RE, Li X, Rich JN and Bao S: Periostin secreted by glioblastoma stem cells recruits M2 tumourassociated macrophages and promotes malignant growth. Nat Cell Biol 17: 170-182, 2015.

13 Martinez FO, Gordon S, Locati $M$ and Mantovani A: Transcriptional profiling of the human monocyte-to-macrophage differentiation and polarization: new molecules and patterns of gene expression. J Immunol 177: 7303-7311, 2006.

14 Gordon S and Martinez FO: Alternative activation of macrophages: mechanism and functions. Immunity 32: 593-604, 2010.

15 Masuoka M, Shiraishi H, Ohta S, Suzuki S, Arima K, Aoki S, Toda S, Inagaki N, Kurihara Y, Hayashida S, Takeuchi S, Koike K, Ono J, Noshiro H, Furue M, Conway SJ, Narisawa Y and Izuhara K: Periostin promotes chroic allergic inflammation in response to Th2 cytokines. J Clin Invest 122: 2590-600, 2012.

16 Sidgwick GP and Bayat A: Extracellular matrix molecules implicated in hypertrophic and keloid scarring. J Eur Acad Dermatol Venereol 26: 141-152, 2012.
17 Wu X, Schulte BC, Zhou Y, Haribhai D, Mackinnon AC, Plaza JA, Williams CB, Hwang ST: Depletion of M2-like tumorassociated macrophages delays cutaneous T-cell lymphoma development in vivo. J Invest Dermatol 134: 2814-2822, 2014.

18 Noy R and Pollard JW: Tumor-associated macrophages: from mechanisms to therapy. Immunity 41: 49-61, 2014.

19 Kakizaki A, Fujimura T, Furudate S, Kambayashi Y, Yamauchi T, Yagita $\mathrm{H}$ and Aiba S: Immunomodulatory effect of peritumorally administered interferon-beta on melanoma through tumorassociated macrophages. Oncoimmunology 4: e1047584, 2015.

20 Frankenberger C, Rabe D, Bainer R, Sankarasharma D, Chada K, Krausz T, Gilad Y, Becker L, Rosner MR: Metastasis Suppressor Regulate the Tumor Microenvironment by Blocking Recruitment of Prometastatic Tumor-Associated Macrophages. Cancer Res 75: 4063-4073, 2015.

21 Bradbury PA, Zhai R, Hopkins J, Kulke MH, Heist RS, Singh S, Zhou W, Ma C, Xu W, Asomaning K, Ter-Minassian M, Wang Z, Su L, Christiani DC and Liu G: Matrix metalloproteinase 1, 3 and 12 polymorphisms and esophageal adenocarcinoma risk and prognosis. Carcinogenesis 30: 793-798, 2009.

22 Stott-Miller M, Houck JR, Lohavanichbutr P, Méndez E, Upton MP, Futran ND, Schwartz SM and Chen C: Tumor and salivary matrix metalloproteinase levels are strong diagnostic markers of oral squamous cell carcinoma. Cancer Epidemiol Biomarkers Prev 20: 2628-36, 2011.

23 Foley CJ and Kuliopulos A: Mouse matrix metalloprotease-1a (Mmp1a) gives new insight into MMP function. J Cell Physiol 229: 1875-1880, 2014.

24 Kim MY, Oskarsson T, Acharyya S, Nguyen DX, Zhang XH, Norton L and Massagué J: Tumor self-seeding by circulating cancer cells. Cell 139: 1315-1326, 2009.

25 Qu P, Du H, Wang X and Yan C: Matrix metalloproteinase 12 overexpression in lung epithelial cells plays a key role in emphysema to lung bronchioalveolar adenocarcinoma transition. Cancer Res 69: 7252-7261, 2009.

26 Ng KT, Qi X, Kong KL, Cheung BY, Lo CM, Poon RT, Fan ST and Man K: Overexpression of matrix metalloproteinase-12 (MMP-12) correlates with poor prognosis of hepatocellular carcinoma. Eur J Cancer 47: 2299-2305, 2011.

27 Kim JM, Kim HJ, Koo BS, Rha KS and Yoon YH: Expression of matrix metalloproteinase-12 is correlated with extracapsular spread of tumor from nodes with metastasis in head and neck squamous cell carcinoma. Eur Arch Otorhinolaryngol 270: 1137 $1142,2013$.
Received April 14, 2017

Revised April 25, 2017

Accepted April 26, 2017 